\title{
Microaggressions Self-Defense: A Role-Playing Workshop for Responding to Microaggressions
}

\author{
Christy M. Byrd \\ Department of Psychology, University of California, Santa Cruz, CA 95064, USA; cmbyrd@ucsc.edu; \\ Tel.: +1-831-459-3970
}

Received: 5 May 2018; Accepted: 9 June 2018; Published: 12 June 2018

\begin{abstract}
Microaggressions are subtle verbal and non-verbal slights based on group membership, and they are ubiquitous in the lives of racial minorities, women, and LGBTQ individuals. The goal of the current paper is to introduce a role-playing based exercise on effective responses to microaggressions. The workshop draws on two previous prejudice responding workshops but integrates research-based strategies.
\end{abstract}

Keywords: microaggressions; responses to microaggressions; role-playing

\section{Introduction}

Microaggressions are subtle verbal and non-verbal slights based on social group membership, and they are ubiquitous in the lives of racial minorities, women, and LGBTQ individuals (Sue 2010). Microaggressions differ from overt forms of discrimination as they are often unintentional or meant in joking manner; nevertheless, they are associated with a host of negative outcomes for individuals who experience them (Sue 2010). For college students in particular, microaggressions have been linked to anxiety, depression, binge drinking, and poor academic performance (Blume 1971; Brown et al. 2015; Ong et al. 2013; Solorzano et al. 2000; Torres et al. 2010; Wong et al. 2014). Since 2007, research on microaggressions has grown exponentially (Wong et al. 2014), and schools and workplaces have sought ways to address them. The current paper describes a research-based role-play workshop designed to teach targets and bystanders effective responses to microaggressions.

The current study draws on two previous studies that described role-play exercises to teach students how to respond to prejudiced comments. First, Plous (2000) described a session in which psychology students were given (or made up) a scenario involving a prejudiced comment where participants rotated through the roles of speaker, responder, and coaches. The speaker would say the prejudiced remark, the responder was instructed to respond in a way that was likely to reduce future prejudice, and the two coaches would give feedback on the response. Plous (2000) reported that students in a seminar on prejudice and discrimination rated the exercise as very valuable and all recommended using it in future classes.

In 2010, Lawson and colleagues (Lawson et al. 2010) evaluated whether a similar workshop would increase students' ability to describe effective responses to prejudiced comments in written scenarios compared to two control groups who did not participate in the exercise. All students were in psychology classes and $87 \%$ were White. The findings showed that students in the experimental class increased their number of effective responses from pre- to post-test, while students in the comparison classes remained the same or decreased.

The current study builds on these findings by presenting a modified exercise. The workshop in the current study was modified in several ways: first, the focus on the workshop was specifically on microaggressions rather than prejudiced comments in general. Because microaggressions are subtle, they can be more difficult to respond to than overt comments, and the strategies take this into account. 
Second, situational factors are discussed as moderators to potential responses. Third, since Plous (2000) and Lawson et al.'s (2010) studies, a large amount of research on how to confront prejudiced comments has emerged, so workshop participants are instructed on effective responses based on a review of this research literature. Fourth, the "coach" role became a "bystander" who could also influence the interaction if they chose, either on the side of the target or the aggressor.

\subsection{Barriers to Responding to Microaggressions}

In this paper, the term "target" is used to refer to the individual whom the remark is directed toward and who is a member of the group(s) stereotyped in the comment (i.e., the target group). An "aggressor" is the person who says or does something that the target interprets as biased. A "bystander" is any person who witnesses the situation but is not the direct target or the aggressor. Bystanders can be targeted or non-targeted. A non-targeted bystander is a bystander who witnesses the situation but is not a member of the stereotyped group, whereas a targeted bystander shares a group identity with the target.

When experiencing microaggressions, targets often feel confused and uncertain about how to respond (Ashburn-Nardo et al. 2008; Czopp et al. 2012; Nadal 2013). Ashburn-Nardo et al. (2008) have identified five barriers responding to discrimination: (1) interpreting the incident as discrimination; (2) deciding whether it is serious enough to warrant a response; (3) taking responsibility for confronting; (4) deciding on a strategy; and (5) responding. Microaggressions have even higher barriers than more blatant forms of discrimination. First, because they are so subtle and ambiguous, microaggressions are especially difficult to notice right away. Additionally, because microaggressions are often said in a joking way or are unintentional, targets may frequently feel that they are not serious enough to warrant interrupting the conversation. Targets may also discount the negative continuing effects of microaggressions, especially if others have told them in the past that they are too sensitive or should just "let it go". Thus, targets may downplay the harm they feel and not confront.

The third barrier of taking responsibility may be similar for microaggressions compared to other forms of discrimination. However, the fourth barrier is raised for microaggressions, because, while individuals may be aware of official procedures for reporting overt discrimination and feel comfortable using them, most organizations do not have similar protocols for reporting microaggressions. Additionally, methods for responding to overt discrimination, such as involving an authority figure, may be seen as inappropriate for microaggressions. Finally, the final barrier for confronting microaggressions is similar to other forms of discrimination. The target must worry about negative repercussions of their actions immediately or in the future. They may also perceive that the confrontation will have little usefulness in changing the aggressor's attitudes or behavior.

In sum, there are many barriers to responding to discrimination, and some of these are heightened for microaggressions. Thus, teaching targets how to respond will likely be seen as valuable; but what strategies are best? Though few studies have examined microaggressions in particular, the prejudice reduction literature does offer some potential strategies for effective responses to biased comments more generally. These are reviewed in the following section.

\subsection{Effective Responses to Prejudiced Comments}

The following review focuses specifically on "in the moment" responses to biased comments rather than other strategies intended to reduce the potential for bias or discrimination (e.g., Focella et al. 2015; Schmader et al. 2013) or to cope long-term. Strategies for responding to prejudiced comments generally fall into two categories: active and passive. Passive strategies include ignoring the comment or withdrawing from the situation. Active strategies include responses such as confrontation and reporting to an authority figure. Research on discrimination in general and microaggressions in particular suggests that active coping strategies are associated with greater well-being later on (Dickter 2012; Grier-Reed 2010; Miller and Major 2000; Solorzano et al. 2000; Torres et al. 2010). In particular, studies on confrontation have found benefits for feelings of 
competence, self-esteem, and the psychological well-being of the target and the reduced prejudice of the aggressor (Czopp et al. 2012, 2006; Czopp and Monteith 2003; Gervais et al. 2010). When they fail to confront, targets may feel guilty and engage in rumination (Sechrist and Swim 2008; Shelton et al. 2006). Bystanders also feel better about themselves when they confront (Dickter 2012; Dickter and Newton 2013). Therefore, the self-defense workshop promotes confrontation as the primary strategy for responding to microaggressions.

For the purposes of the workshop, confrontation is defined as when the target verbally or non-verbally expresses displeasure with the aggressor's behavior (Focella et al. 2015). Confrontation can be especially effective when the goal is to reduce the potential of future prejudiced comments in aggressors and bystanders. Individuals who are confronted over prejudiced remarks are less likely to make biased remarks later (Czopp et al. 2006) and are better able to detect prejudice (Mallett and Wagner 2011). They may also attempt to compensate for their behavior to repair their relationship with the target (Mallett and Wagner 2011). Confrontation is effective because it induces negative self-directed affect such as guilt and concern over discrepancies between the aggressor's self-concept (i.e., egalitarian values) and behavior (Czopp et al. 2006; Monteith et al. 2002). Such feelings can lead the individuals to try to be more aware of their bias and to correct their behavior to be more consistent with their self-concepts (Czopp et al. 2006). Furthermore, the positive effects of confrontation are not limited to aggressors: bystanders also reduce their likelihood of prejudiced responding when overhearing or witnessing confrontation (Blanchard et al. 1994; Monteith et al. 1996).

The downside to confrontation is that aggressors tend to see the target who confronts as rude, a complainer, or hypersensitive (Czopp and Monteith 2003; Gulker et al. 2013; Kaiser and Miller 2003; Rasinski and Czopp 2010), especially when the prejudice is subtle (Dodd etal.2001; Saunders and Senn 2009) and the confrontation more aggressive (Swim and Thomas 2006). However, some studies report that aggressors increase their liking for the confronting target and try to make amends (Hyers 2010; Mallett and Wagner 2011). Non-targeted bystanders are also more likely to see the target in a negative light regardless of how prejudiced they judge the behavior (Dodd et al. 2001; Kaiser and Miller 2003; Rasinski and Czopp 2010). On the other hand, bystanders who share the target's group membership respect and like targets more when they confront rather than not (Dodd et al. 2001). The negative evaluation does not seem to occur for non-targeted bystanders who confront (Boysen 2013; Dickter et al. 2012; Kowalski 1996). In the end, confrontation is effective but has the potential to create a backlash.

Some types of confrontation are more effective than others. Generally, angry and hostile confrontations are likely to be seen as violating norms of politeness and may increase the chance of backlash (Czopp et al. 2006; Hyers 2010). One study found that men imagining themselves as aggressors were more likely to rate hostile confronters as irritating and unlikeable than confronters who used less hostile strategies (Saunders and Senn 2009). Additionally, describing an incident as discrimination may also provoke a stronger negative response than milder forms of disagreement. In one study, participants imagined witnessing one of three responses to a racist or sexist joke: (1) labeling the joke as racist/sexist; (2) saying the joke was not funny; (3) ignoring the joke. The participants rated the appropriateness of the response and how much they liked the target. For the racist joke, labeling a joke as racist or saying it was not funny was seen as more appropriate than ignoring it. There was no significant difference between the two confrontation styles and the confronter was equally liked. Nevertheless, for a sexist joke, saying that it was not funny was rated as more appropriate than calling it sexist (or ignoring it) and confronters were rated as most likeable when they gave that response (Woodzicka et al. 2015).

Additional research suggests that confronted aggressors feel less anger and irritation when confronted with messages focused on fairness (e.g., "Maybe it would be good to think about Blacks in other ways that are a little more fair?") rather than a message focused on prejudice (e.g., "You should really try to think about Blacks in other ways that are less prejudiced"), although both messages were associated with less prejudiced responses later (Czopp et al. 2006). Therefore, the most useful 
confrontation strategy may be to focus on positives, such as calling attention to the aggressor's egalitarian values.

The literature on confrontation is limited because it does not consider microaggressions in particular and the samples are mostly White college students in experimental situations (Czopp and Ashburn-Nardo 2012; Focella et al. 2015). Few studies examine responses in naturalistic settings or how responses vary according to situational parameters. Nevertheless, when the goal is prejudice reduction, the literature suggests that targets should use strategies that are (1) active, (2) do not violate norms of politeness, and (3) focus on positive qualities rather than accusations. The next section will explain a workshop that can teach effective confrontation.

\subsection{The Microaggressions Self-Defense Workshop}

The self-defense workshop is designed to be conducted in an hour to an hour and a half and in groups of almost any size. The handout in the Appendix A can be used as visual aid. The workshop begins with an introduction to microaggressions: what they are, examples, and what research says about their effects (see Appendix B). While acknowledging that most people do not confront aggressors, the facilitators highlight reasons why confrontation may be a useful strategy.

\subsubsection{Your Goal}

Before presenting the strategies, facilitators note two situational factors to consider when thinking about when and how to respond to microaggressions: (1) your goal and (2) your role. Goal refers to what kind of resolution the individual seeks. For example, targets who merely want to interrupt a situation in which a microaggression is expressed may choose humor as a response compared to those who want to educate the aggressor. Some other reasons that individuals confront prejudice are to release anger or frustration, to affirm their own values, to manage impressions to present themselves in a favorable light, to gain information about others' (i.e., bystanders') views, and to avoid feeling guilty or ruminating later. Since the research on responding to prejudiced comments universally considers reducing the potential of future bias as the goal, some responses may not be appropriate for other goals.

\subsubsection{Your Role}

Role refers to considering the relationship between the target, the aggressor, and bystanders. For example, employees may feel more threatened when deciding to confront their boss compared to a co-worker. Friends may both be more effective confronters (because the aggressor is motivated to preserve the relationship) or less effective (because the confrontation is perceived as less serious) (Czopp and Ashburn-Nardo 2012). It may be easier to confront as a target than as a bystander who overhears a microaggression because the target is already involved in the interaction. However, a confrontation from a bystander who shares the aggressor's identity can be more effective because targets are expected to confront and are seen as less credible and less persuasive (Czopp and Ashburn-Nardo 2012). Other factors are also at play in the situation, such as the aggressor's level of prejudice and personality factors like agreeableness (Czopp and Ashburn-Nardo 2012). However, these are not likely to be known by the target or bystanders. The type of bias (i.e., racial, gender) could also be considered, as one study has found that gender bias is perceived as less worthy of confrontation than racial bias (Czopp and Monteith 2003).

\subsubsection{The Strategies}

After discussing the situational factors, facilitators present the eight strategies, each of which meets the criteria of being active, polite, and positive (Hillard 2011; Nadal 2013; Plous 2000; Sue 2003, 2010; Swim and Thomas 2006): 
(1) Appeal to values: for example, saying "I've always thought of you as an open-minded person who wouldn't say things like that." Appealing to the aggressor's positive values, particularly of fairness and egalitarianism, feels counter-intuitive because the aggressor is displaying behavior contrary to those values. However, research suggests that making the aggressor aware of this very discrepancy induces feelings of guilt and motivation to make their behavior more in line with their values (Czopp et al. 2006; Dovidio et al. 2000; Monteith 1993; Monteith et al. 2002). This strategy may be most effective for those lower in prejudice, because high-prejudiced individuals are less likely to find their behavior problematic (Czopp et al. 2006; Dovidio et al. 2000; Monteith 1993). One the other hand, a study of high-prejudice individuals that had the participants reflect on their values before reading a personal website about the discrimination an Arab-American faced increased behaviors such as wanting to get to know the person better compared to a condition where participants did not reflect on their values (Stone et al. 2011). This study did not examine direct confrontation, however.

(2) Express your feelings, particularly of hurt or disappointment: this strategy can also induce the value-behavior discrepancy, especially when the target and aggressor have a close relationship and/or the remark is meant as a joke. This approach can also call for perspective-taking and create empathy, which has been shown to reduce stereotyping and denial of discrimination (Todd et al. 2012; Vescio et al. 2003). This approach has the potential to backfire, however, with high-prejudice individuals and if the perspective-taking requires a high amount of effort (Stone et al. 2011; Vorauer et al. 2009).

(3) Get the aggressor to explain, for example, asking "What did you mean by that?": "playing dumb" and asking for further information can be useful for highlighting logical inconsistencies in the aggressor's words or uncovering unconscious bias. It can also provide an opportunity for the confronter to introduce information to correct a false belief.

(4) Empathize with the underlying feeling, for example, by saying, "I know it's hard to find a job after college, but affirmative action isn't the problem": using empathy can help the aggressor see the target as having similar values and promote inclusion of the other in the self, where another's attributes are seen as part of one's self-concept (Tropp and Wright 2001). Affirming the aggressor can also reduce feelings of threat, which has been shown reduce bias in intergroup interactions (Fein and Spencer 1997; Greenberg et al. 1997; Spencer et al. 1998) and make aggressors more willing to acknowledge guilt after a biased action (Gunn and Wilson 2011). Some studies suggest that affirmation is more effective for high-prejudice individuals than other strategies (e.g., Sinclair and Kunda 1999).

(5) Give information that contradicts the aggressor or gives a new perspective on the issue: for example, if a White aggressor assumes that a Black target grew up in a single-parent family, the target can explain that they grew up with both parents. Providing counter-stereotypic information about one's self is a form of individuation than can be effective for reducing prejudice (Blair and Banaji 1996; Blair et al. 2001; Dasgupta and Greenwald 2001). However, by presenting oneself as counter-stereotypic, a target may resolve prejudice against them in the moment but reinforce prejudice against their group (Focella et al. 2015). Alternatively, the target can present statistics or data that contradicts the aggressor, for example, by explaining wage disparities between men and women. This strategy requires a high level of preparation, as the confronter will need to be familiar with relevant data.

(6) Use humor: humor may reduce defensiveness compared to more challenging approaches (Swim and Thomas 2006), but also strongly relies on the confronter's personality.

(7) Involve others: when no one responds to prejudiced comments, a community norm allowing those comments is set. By confronting, targets and bystanders set the opposite norm (Monteith et al. 1996; Stangor et al. 2001). Involving others can be a strategy to invoke "safety in numbers" to highlight the norm violation to the aggressor. 
(8) Non-verbal response: finally, a non-verbal response such as a look or sigh may still be impactful without requiring a high level of preparation or energy from the confronter.

\subsubsection{Role-Play Practice}

After learning about the strategies, participants are given a list of scenarios or asked to generate their own. Example scenarios and potential responses are in Appendix B. They then divide into triads and role play each scenario, with the target (and bystander, if they choose), using one of the taught strategies to respond. The groups discuss the effectiveness of the response(s) and rotate through each role. After about half an hour, the facilitators lead a large group discussion focusing on participants' reactions to the role play and their ideas about which strategies would be most successful when. Facilitators should encourage participants to fit the strategies to their own circumstances.

\section{Discussion}

The Microaggressions Self-Defense Workshop is a useful strategy for preparing participants to respond to microaggressions. It can be used in a classroom setting to teach about prejudice and discrimination or as a workshop in work settings. This workshop differed from previous demonstrations (Lawson et al. 2010; Plous 2000) because we utilize research on confronting prejudice to teach the students effective strategies. Using these skills can help college students protect their own well-being as well as reduce the prevalence of microaggressions on their campuses by setting positive norms (Monteith et al. 1996; Stangor et al. 2001). Other strategies may also be successful, but the eight presented here represent a manageable set to remember and a range of types of confrontation.

Research remains to be done on the effectiveness of different responses and on how best to teach targets and bystanders to respond. In the meantime, however, the Microaggressions Self-Defense Workshop shows promise as a teaching method and intervention that combines active-learning strategies with the latest psychological research to help reduce prejudice and promote environments of inclusivity and acceptance.

Funding: This work was funded by the University of California, Santa Cruz Committee on Research.

Conflicts of Interest: The authors declare no conflict of interest. The founding sponsors had no role in the design of the study; in the collection, analyses, or interpretation of data; in the writing of the manuscript, and in the decision to publish the results. 


\section{Appendix A}

Responding to Microaggressions Handout

Note: Full size PDF available at https://doi.org/10.7291/D1DT0M

\section{Responding to Microaggressions}

\section{What is a microaggression?}

Microaggressions are subtle verbal or non-verbal slights and indignities based on membership in a social group. They are a form of discrimination and are hurtful even though they are sometimes unintentional or meant in a joking way. We refer to the person who says/does the microaggression as the aggressor and the person who they are speaking to as the target.

\section{Why confront microaggressions?}

Most people don't confront microaggressions, but confronting can help the other person to realize their bias and change their behavior. Confronting also sets a norm that the behavior isn't OK, so people around are less likely to do or say something similar. When thinking about responding, consider:

\section{Your goal}

-What do you want to accomplish?

\section{How do I respond?}

When your goal is to affect someone's bias, the most effective responses are polite rather than hostile and focus on positive qualities rather than accusations of prejudice.

\begin{tabular}{|c|c|}
\hline Appeal to values & - "You're too smart to believe that!" \\
\hline Express your feelings & • "That hurts my feelings." \\
\hline Get them to explain & ."What did you mean by that?" \\
\hline Empathize with the underlying feeling & -"I know it's hard to find a job after college, [but affirmative action isn't the problem.]" \\
\hline Give information & - "Actually, most people on welfare are White." \\
\hline Use humor & - "Wow, you sound like my grandpa" \\
\hline Involve others & •"Did you hear that?" \\
\hline Non-verbal response & - Roll your eyes \\
\hline
\end{tabular}

\section{How might they react?}

Most people feel negative emotions when they are confronted, but they can still learn from the experience. Here are some common reactions:

- Anger

- Denial

- Dismissal/minimization

- Attack

- Claim it was a joke
- Try to explain your misinterpretation

- Guilt or shame

- Freeze
- Get others to agree with them

- Apologize/try to make up for it

Figure A1. Workshop Handout. 


\section{Appendix B}

Definition of Microaggressions, Examples, and Effects

Definition: Microaggressions are subtle and often unintentional verbal or nonverbal slights that demean an individual based on their membership in a marginalized group (Sue 2010).

\section{Examples of Microaggressions}

- $\quad$ Being stared at in the dining hall

- Someone asking to touch your hair because it is "exotic"

- Being told you speak English well when it is your first language

- Being mistaken for someone in a service role

- To an Asian person, "You must be good in math, can you help me with this problem?"

- Someone crosses to the other side of the street to avoid a person of color

- A gay/lesbian person being told "You don't look gay"

\section{Effects of Experiencing Microaggressions}

- Psychological effects
$\circ \quad$ Anxiety
- Depressive symptoms
- Lower self-esteem

- $\quad$ Academic effects
- Lower feelings of belonging
- Lack of confidence in abilities
- Poor performance
- Dropping out of school

\section{Examples of Responses}

Table A1. Examples of Responses.

\begin{tabular}{lll}
\hline Microaggressions & Strategy & Response \\
\hline $\begin{array}{l}\text { "You don't look gay." } \\
\begin{array}{l}\text { Someone asking to touch your hair } \\
\text { because it is "exotic" }\end{array}\end{array}$ & Expeal to values & $\begin{array}{l}\text { "Wow, I didn't think you were the kind } \\
\text { of person to make assumptions about } \\
\text { people." }\end{array}$ \\
$\begin{array}{l}\text { "You must be good in math, can you } \\
\text { help me with this problem?" }\end{array}$ & Get them to explain & $\begin{array}{l}\text { "It makes me uncomfortable that you } \\
\text { want to touch my hair." }\end{array}$ \\
\hline $\begin{array}{l}\text { "How do Black people feel about } \\
\text { good at math?" }\end{array}$ & $\begin{array}{l}\text { Empathize with the } \\
\text { affirmative action?" }\end{array}$ & $\begin{array}{l}\text { "It's great that you're curious, but not } \\
\text { all Black people have the same opinion } \\
\text { about things. My opinion is ... " }\end{array}$ \\
\hline $\begin{array}{l}\text { "Of course she'll get the job, } \\
\text { she's a minority." }\end{array}$ & Give information & $\begin{array}{l}\text { "It's actually harder for minorities to get } \\
\text { those jobs. I read a study about it." }\end{array}$ \\
\hline $\begin{array}{l}\text { Being told you speak English well } \\
\text { when it is your first language }\end{array}$ & Use humor & $\begin{array}{l}\text { "Thanks, I've been speaking it since I } \\
\text { was born!" }\end{array}$ \\
\hline $\begin{array}{l}\text { Someone assumes you speak Spanish } \\
\text { because you look Latino/a. }\end{array}$ & Involve others & $\begin{array}{l}\text { Turn to a friend: "Apparently, I speak } \\
\text { Spanish now. Who knew?" }\end{array}$ \\
\hline
\end{tabular}




\section{References}

Ashburn-Nardo, Leslie, Kathryn A. Morris, and Stephanie A. Goodwin. 2008. The confronting prejudiced responses (CPR) model: Applying CPR in organizations. Academy of Management Learning $\mathcal{E}$ Education 7: $332-42$.

Blair, Irene V., and Mahzarin R. Banaji. 1996. Automatic and controlled processes in stereotype priming. Journal of Personality and Social Psychology 70: 1142-63. [CrossRef]

Blair, Irene V., Jennifer E. Ma, and Alison P. Lenton. 2001. Imagining stereotypes away: The moderation of implicit stereotypes through mental imagery. Journal of Personality and Social Psychology 81: 828-41. [CrossRef] [PubMed]

Blanchard, Fletcher A., Chris S. Crandall, John C. Brigham, and Leigh Ann Vaughn. 1994. Condemning and condoning racism: A social context approach to interracial settings. Journal of Applied Psychology 79: 993-97. [CrossRef]

Blume, Norman. 1971. Open Housing Referenda. Public Opinion Quarterly 35: 563-70. [CrossRef]

Boysen, Guy A. 2013. Confronting math stereotypes in the classroom: Its effect on female college students' sexism and perceptions of confronters. Sex Roles 69: 297-307. [CrossRef]

Brown, Bryan A., J. Bryan Henderson, Salina Gray, Brian Donovan, Shayna Sullivan, Alexis Patterson, and William Waggstaff. 2015. From description to explanation: An empirical exploration of the African American pipeline problem in STEM. Journal of Research in Science Teaching. [CrossRef]

Czopp, Alexander M., and Leslie Ashburn-Nardo. 2012. Interpersonal confrontations of prejudice. In The Psychology of Prejudice: Interdisciplinary Perspectives on Contemporary Issues. Edited by W. Russell and C. A. Russell. Hauppauge: Nova Science Publishers, Inc.

Czopp, Alexander M., and Margo J. Monteith. 2003. Confronting prejudice (literally): Reactions to confrontations of racial and gender bias. Personality and Social Psychology Bulletin 29: 532-44. [CrossRef] [PubMed]

Czopp, Alexander M., Margo J. Monteith, and Aimee Y. Mark. 2006. Standing up for a change: Reducing bias through interpersonal confrontation. Journal of Personality and Social Psychology 90: 784-803. [CrossRef] [PubMed]

Czopp, A. M., L. Ashburn-Nardo, W. Russell, and C. A. Russell. 2012. Interpersonal confrontations of prejudice. In The Psychology of Prejudice: Interdisciplinary Perspectives on Contemporary Issues. Hauppauge: Nova Science Publishers, Inc.

Dasgupta, Nilanjana, and Anthony G. Greenwald. 2001. On the malleability of automatic attitudes: Combating automatic prejudice with images of admired and disliked individuals. Journal of Personality and Social Psychology 81: 800-14. [CrossRef] [PubMed]

Dickter, Cheryl L. 2012. Confronting hate: Heterosexuals' responses to anti-gay comments. Journal of Homosexuality 59: 1113-30. [CrossRef] [PubMed]

Dickter, Cheryl L., and Virginia A. Newton. 2013. To confront or not to confront: Non-targets' evaluations of and responses to racist comments. Journal of Applied Social Psychology 43: E262-75. [CrossRef]

Dickter, Cheryl L., Julie A. Kittel, and Ivo I. Gyurovski. 2012. Perceptions of non-target confronters in response to racist and heterosexist remarks. European Journal of Social Psychology 42: 112-19. [CrossRef]

Dodd, Elizabeth H., Traci A. Giuliano, Jori M. Boutell, and Brooke E. Moran. 2001. Respected or rejected: Perceptions of women who confront sexist remarks. Sex Roles 45: 567-77. [CrossRef]

Dovidio, John. F., Kawakami Kerry, and Sam L. Gaertner. 2000. Reducing contemporary prejudice: Combating explicit and implicit bias at the individual and intergroup level. In "The Claremont Symposium on Applied Social Psychology" Reducing prejudice and discrimination. Edited by Stuart Oskamp. Mahwah: Lawrence Erlbaum Associates Publishers, pp. 137-163.

Fein, Steven, and Steven J. Spencer. 1997. Prejudice as self-image maintenance: Affirming the self through derogating others. Journal of Personality and Social Psychology 73: 31-44. [CrossRef]

Focella, Elizabeth S., Meghan G. Bean, and Jeff Stone. 2015. Confrontation and beyond: Examining a stigmatized target's use of a prejudice reduction strategy. Social and Personality Psychology Compass 9: 100-14. [CrossRef]

Gervais, Sarah J., Amy L. Hillard, and Theresa K. Vescio. 2010. Confronting sexism: The role of relationship orientation and gender. Sex Roles 63: 463-74. [CrossRef] 
Greenberg, Jeff, Sheldon Solomon, and Tom Pyszczynski. 1997. Terror management theory of self-esteem and cultural worldviews: Empirical assessments and conceptual refinements. Advances in Experimental Social Psychology 29: 61-139.

Grier-Reed, Tabitha L. 2010. The African American Student Network: Creating sanctuaries and counterspaces for coping with racial microaggressions in higher education settings. The Journal of Humanistic Counseling, Education and Development 49: 181-88. [CrossRef]

Gulker, Jill E., Aimee Y. Mark, and Margo J. Monteith. 2013. Confronting prejudice: The who, what, and why of confrontation effectiveness. Social Influence 8: 280-93. [CrossRef]

Gunn, Gregory R., and Anne E. Wilson. 2011. Acknowledging the skeletons in our closet: The effect of group affirmation on collective guilt, collective shame, and reparatory attitudes. Personality and Social Psychology Bulletin 37: 1474-84. [CrossRef] [PubMed]

Hillard, Amy. 2011. Why Confronting Sexism Works: Applying Persuasion Theories to Confronting Sexism. Available online: http:/ / digitalcommons.unl.edu/psychdiss/35/ (accessed on July 17 2017).

Hyers, L. L. 2010. Alternatives to silence in face-to-face encounters with everyday heterosexism: Activism on the interpersonal front. Journal of Homosexuality 57: 539-65. [CrossRef] [PubMed]

Kaiser, Cheryl R., and Carol T. Miller. 2003. Derogating the victim: The interpersonal consequences of blaming events on discrimination. Group Processes E Intergroup Relations 6: 227-37.

Kowalski, Robin M. 1996. Complaints and complaining: Functions, antecedents, and consequences. Psychological Bulletin 119: 179-96. [CrossRef] [PubMed]

Lawson, Timothy J., Tracy A. McDonough, and James H. Bodle. 2010. Confronting prejudiced comments: Effectiveness of a role-playing exercise. Teaching of Psychology 37: 257-61. [CrossRef]

Mallett, Robyn K., and Dana E. Wagner. 2011. The unexpectedly positive consequences of confronting sexism. Journal of Experimental Social Psychology 47: 215-20. [CrossRef]

Miller, Carol T., and Brenda Major. 2000. Coping with stigma and prejudice. In The Social Psychology of Stigma. New York: Guilford Press, pp. 243-72.

Monteith, Margo J. 1993. Self-regulation of prejudiced responses: Implications for progress in prejudice-reduction efforts. Journal of Personality and Social Psychology 65: 469-85. [CrossRef]

Monteith, Margo J., Nicole E. Deneen, and Gregory D. Tooman. 1996. The effect of social norm activation on the expression of opinions concerning gay men and Blacks. Basic and Applied Social Psychology 18: 267-88. [CrossRef]

Monteith, Margo J., Ashburn-Nardo Leslie, Corrine I. Voils, and Alexander M. Czopp. 2002. Putting the brakes on prejudice: On the development and operation of cues for control. Journal of Personality and Social Psychology 83: 1029-50. [CrossRef] [PubMed]

Nadal, Kevin L. 2013. Processes of Dealing with Microaggressions. Washington: American Psychological Association, pp. 152-73.

Ong, Anthony D., Anthony L. Burrow, Thomas E. Fuller-Rowell, Nicole M. Ja, and Derald W. Sue. 2013. Racial microaggressions and daily well-being among Asian Americans. Journal of Counseling Psychology 60: 188-99. [CrossRef] [PubMed]

Plous, Scott. 2000. Responding to overt displays of prejudice: A role-playing exercise. Teaching of Psychology 27: 198-200. [CrossRef]

Rasinski, Heather M., and Alexander M. Czopp. 2010. The effect of target status on witnesses' reactions to confrontations of bias. Basic and Applied Social Psychology 32: 8-16. [CrossRef]

Saunders, Kristin A., and Charlene Y. Senn. 2009. Should I confront him? Men's reactions to hypothetical confrontations of peer sexual harassment. Sex Roles 61: 399-415. [CrossRef]

Schmader, Toni, Alyssa Croft, Jessica Whitehead, and Jeff Stone. 2013. A peek inside the targets' toolbox: How stigmatized targets deflect discrimination by invoking a common identity. Basic and Applied Social Psychology 35: 141-49. [CrossRef]

Sechrist, Gretchen B., and Janet K. Swim. 2008. Psychological consequences of failing to attribute negative outcomes to discrimination. Sex Roles 59: 21-38. [CrossRef]

Shelton, J. Nicole, Jennifer A. Richeson, Jessica Salvatore, and Diana M. Hill. 2006. Silence is not golden: The intrapersonal consequences of not confronting prejudice. In Stigma and Group Inequality: Social Psychological Perspectives. Mahwah: Lawrence Erlbaum Associates Publishers, pp. 65-81. 
Sinclair, Lisa, and Ziva Kunda. 1999. Reactions to a black professional: Motivated inhibition and activation of conflicting stereotypes. Journal of Personality and Social Psychology 77: 885-904. [CrossRef] [PubMed]

Solorzano, Daniel, Miguel Ceja, and Tara Yosso. 2000. Critical race theory, racial microaggressions, and campus racial climate: The experiences of African American college students. Journal of Negro Education 69: 60-73.

Spencer, Steven J., Steven Fein, Connie T. Wolfe, Christina Fong, and Meghan A. Duinn. 1998. Automatic activation of stereotypes: The role of self-image threat. Personality and Social Psychology Bulletin 24: 1139-52. [CrossRef]

Stangor, Charles, Gretchen B. Sechrist, and John T. Jost. 2001. Changing racial beliefs by providing consensus information. Personality and Social Psychology Bulletin 27: 486-96. [CrossRef]

Stone, Jeff, Jessica Whitehead, Toni Schmader, and Elizabeth Focella. 2011. Thanks for asking: Self-affirming questions reduce backlash when stigmatized targets confront prejudice. Journal of Experimental Social Psychology 47: 589-98. [CrossRef]

Sue, Derald Wing. 2003. Overcoming Our Racism: The Journey to Liberation. San Francisco: Jossey-Bass.

Sue, Derald Wing. 2010. Microaggressions in Everyday Life: Race, Gender, and Sexual Orientation. Hoboken: John Wiley \& Sons.

Swim, Janet K., and Margaret A. Thomas. 2006. Responding to everyday discrimination: A synthesis of research on goal-directed, self-regulatory coping behaviors. In Stigma and Group Inequality: Social Psychological Perspectives. Abingdon: Taylor \& Francis Group, pp. 105-26.

Todd, Andrew R., Galen V. Bodenhausen, and Adam D. Galinsky. 2012. Perspective taking combats the denial of intergroup discrimination. Journal of Experimental Social Psychology 48: 738-45. [CrossRef]

Torres, Lucas, Mark W. Driscoll, and Anthony L. Burrow. 2010. Racial microaggressions and psychological functioning among highly achieving African-Americans: A mixed-methods approach. Journal of Social and Clinical Psychology 29: 1074-99. [CrossRef]

Tropp, Linda R., and Stephen C. Wright. 2001. Ingroup identification as the inclusion of ingroup in the self. Personality and Social Psychology Bulletin 27: 585-600. [CrossRef]

Vescio, Theresa K., Gretchen B. Sechrist, and Matthew P. Paolucci. 2003. Perspective taking and prejudice reduction: The mediational role of empathy arousal and situational attributions. European Journal of Social Psychology 33: 455-72. [CrossRef]

Vorauer, Jacquie D., Verena Martens, and Stacey J. Sasaki. 2009. When trying to understand detracts from trying to behave: Effects of perspective taking in intergroup interaction. Journal of Personality and Social Psychology 96: 811-27. [CrossRef] [PubMed]

Wong, Gloria, Anne O. Derthick, E. J. R. David, Anne Saw, and Sumie Okazaki. 2014. The what, the why, and the how: A review of racial microaggressions research in psychology. Race and Social Problems 6: 181-200. [CrossRef] [PubMed]

Woodzicka, Julie A., Robyn K. Mallett, Shelbi Hendricks, and Astrid V. Pruitt. 2015. It's just a (sexist) joke: Comparing reactions to sexist versus racist communications. HUMOR 28: 289-309. [CrossRef]

(C) 2018 by the author. Licensee MDPI, Basel, Switzerland. This article is an open access article distributed under the terms and conditions of the Creative Commons Attribution (CC BY) license (http://creativecommons.org/licenses/by/4.0/). 